\title{
Gradient Increase
}

National Cancer Institute

\section{Source}

National Cancer Institute. Gradient Increase. NCI Thesaurus. Code C63126.

Problem associated with the increased rate of change in temperature, pressure, or other variables as a function of distance, time, etc. 